\title{
A double-blind, randomized phase II study of dicycloplatin plus paclitaxel versus carboplatin plus paclitaxel as first-line therapy for patients with advanced non-small-cell lung cancers
}

Ke-Jun Liu', ${ }^{1,2}$, Zhong-Zhen Guan ${ }^{1}$, Ying Liang ${ }^{1}$, Xu-Qing Yang ${ }^{3}$, Jin Peng ${ }^{1}$, He Huang ${ }^{1}$, Qing-Xiang Shao ${ }^{4}$,

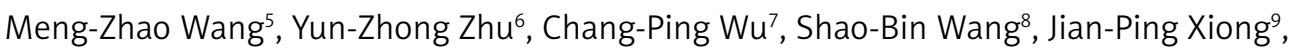
Yu-Xian Bai ${ }^{10}$, Shi-Ying Yu ${ }^{11}$, Yang Zhang ${ }^{12}$, Xiao-Hua Hu ${ }^{13}$, Ji-Feng Feng ${ }^{14}$, Shi-Xiu Wu ${ }^{15}$, Shun-Chang Jiao ${ }^{16}$, Cai-Cun $\mathrm{Zhou}^{17}$, Jie Wang ${ }^{18}$, Hai-Ying Wu ${ }^{1}$

${ }^{1}$ State Key Laboratory of Oncology in South China, Sun Yat-Sen University Cancer Center, Guangzhou, China

2Department of Medical Oncology, Dongguan People's Hospital, Dongguan, China ${ }^{3}$ College of Chemistry and Molecular Engineering, Peking University, Beijing, China ${ }^{4}$ Institute of Materia Medica, Zhejiang Academy of Medical Science, Hangzhou, China ${ }^{5}$ Department of Respiratory Medicine, Peking Union Medical College Hospital, Peking Union Medical College and Chinese Academy of Medical Sciences, Beijing, China ${ }^{6}$ Department of Oncology, Beijing Chest Hospital, Capital Medical University, Beijing, China

${ }^{7}$ Department of Oncology, Third Affiliated Hospital of Soochow University,

Changzhou, China

${ }^{8}$ Department of Internal Medicine, First Affiliated Hospital of Shantou University, Shantou, China

${ }^{9}$ Department of Oncology, First Affiliated Hospital of Nanchang University, Nanchang, China

${ }^{10}$ Department of Medical Oncology, Affiliated Tumor Hospital of Harbin Medical University, Harbin, China

${ }^{11}$ Tongji Cancer Center, Tongji Hospital, Tongji Medical College, Huazhong University of Science and Technology, Wuhan, China

${ }^{12}$ Department of Medical Oncology, Second Affiliated Hospital of Dalian Medical University, Dalian, China

${ }^{13}$ Department of Oncology, Affiliated Tumor Hospital of Guangxi Medical University, Nanning, China

${ }^{14}$ Department of Oncology, Jiangsu Cancer Hospital, Nanjing, China

${ }^{15}$ Department of Radiation Oncology, First Hospital, Wenzhou Medical College, Wenzhou, China

${ }^{16}$ Department of Medical Oncology, Cancer Center, Chinese PLA General Hospital, Beijing, China

${ }^{17}$ Department of Medical Oncology, Shanghai Pulmonary Hospital, Shanghai, China

${ }^{18}$ Department of Medical Oncology, Beijing Institute for Cancer Research, Beijing, China

Submitted: 13 August 2013

Accepted: 11 November 2013

Arch Med Sci 2014; 10, 4: 717-724

DOI: 10.5114 /aoms.2014.44862

Copyright @ 2014 Termedia \& Banach

\section{Abstract}

Introduction: The aim of this study was to compare the efficacy and toxicity of dicycloplatin plus paclitaxel with those of carboplatin plus paclitaxel as firstline treatment for patients with advanced non-small-cell lung cancer (NSCLC). Material and methods: In this study, 240 NSCLC patients with stage IIIB (with pleural effusion) and stage IV disease were randomly assigned $(1: 1)$ to receive dicycloplatin $450 \mathrm{mg} / \mathrm{m}^{2}$ or carboplatin $A U C=5$, in combination with paclitaxel $175 \mathrm{mg} / \mathrm{m}^{2}(\mathrm{D}+\mathrm{P}$ or $\mathrm{C}+\mathrm{P}$ ) every 3 weeks for up to 4 to 6 cycles. The primary endpoint was response rate. Secondary endpoints included progression-free survival (PFS), overall survival (OS) and adverse events.

\author{
Corresponding author: \\ Hai Ying Wu \\ State Key Laboratory \\ of Oncology \\ in South China \\ Sun Yat-Sen University \\ Cancer Center \\ 651 Dongfeng Road East \\ Guangzhou 510060, China \\ Phone: +86 37396924572 \\ E-mail: jiwen0005@126.com
}


K.J. Liu, Z.Z. Guan, Y. Liang, X.Q. Yang, J. Peng, H. Huang, Q.X. Shao, M.Z. Wang, Y.Z. Zhu, C.P. Wu, S.B. Wang, J.P. Xiong, Y.X. Bai, S.Y. Yu, Y. Zhang, X.H. Hu, J.F. Feng, S.X. Wu, S.C. Jiao, C.C. Zhou, J. Wang, H.Y. Wu

Results: The response rates for the $\mathrm{D}+\mathrm{P}$ and $\mathrm{C}+\mathrm{P}$ arm were $36.44 \%$ and $30.51 \%$, respectively $(p=0.33)$. The median PFS was 5.6 months in the $\mathrm{D}+\mathrm{P}$ arm and 4.7 months in the $\mathrm{C}+\mathrm{P}$ arm $(p=0.31)$. The median OS was 14.9 months for $\mathrm{D}+\mathrm{P}$ and 12.9 months for $\mathrm{C}+\mathrm{P}(p=0.37)$. Adverse events in the two arms were well balanced. The most common grade $3 / 4$ adverse event was hematologic toxicity.

Conclusions: Patients treated with $\mathrm{D}+\mathrm{P}$ had similar response and survival rates to those treated with $\mathrm{C}+\mathrm{P}$, and toxicities of both treatments were generally tolerable.

Key words: dicycloplatin, platinum derivative, first-line therapy, non-small-cell lung cancer (NSCLC), phase II study.

\section{Introduction}

Lung cancer is one of the most common cancers worldwide, and is also the primary cause of deaths resulting from malignant tumors [1]. Lung cancer is currently classified into two different types, small-cell lung cancer (SCLC) and nonsmall-cell lung cancer (NSCLC). Common treatments include surgery, chemotherapy, and radiotherapy. The NSCLC is sometimes treated with surgery, whereas SCLC usually responds better to chemotherapy and radiotherapy [2]. Patients with NSCLC often have an advanced stage at the time of diagnosis, with a 1-year survival rate of about 10-15\% even under the best support treatment [3]. The majority of patients with advanced NSCLC may benefit from standard platinum-based chemotherapy, obtaining a median survival time of 8 to 10 months [4-7].

Previous studies have found that the combination therapy of carboplatin and paclitaxel for patients with NSCLC produced good results, improving both overall survival and quality of life when compared to support treatment $[8,9]$. The regimen of carboplatin AUC $=5$ and paclitaxel $175 \mathrm{mg} / \mathrm{m}^{2}$ administered every 3 weeks is safe and effective [10]. However, the efficacy of this combination as first-line treatment of advanced NSCLC can only be maintained for 4-6 cycles, as increased cycles do not further improve clinical efficacy [11]. In addition, the cost of carboplatin and paclitaxel seems a little high for patients living in developing countries. Therefore, it is necessary to develop a new regimen with lower expense and higher effectiveness.

Dicycloplatin is a novel platinum derivative which contains two naphthenic diacids within its molecular structure. It was synthesized by Beijing Xing-Da Scientific System Corporation (Beijing, China). Dicycloplatin has independent intellectual property rights all over the world (U.S. Patent No. 6699901B1; European Patent No. 1186610; Japanese Patent No. 3697210 and Chinese Patent No. 94103448.8). Dicycloplatin is an antitumor agent, with a mechanism similar to carboplatin and cisplatin. The chemical name of dicycloplatin is cis-diammine (1,1-cyclobutane dicarboxylate) platinum (II),1,1-cyclobutane carboxylic acid com- plex, with the molecular formula $\mathrm{C}_{12} \mathrm{H}_{20} \mathrm{~N}_{2} \mathrm{O}_{8} \mathrm{Pt}$ and a molecular weight of 515.39. The hydrosolubility of dicycloplatin is $4 \mathrm{~g} / \mathrm{ml}$, which is more potent than carboplatin $(1.5 \mathrm{mg} / \mathrm{ml})$ and cisplatin $(0.2 \mathrm{mg} / \mathrm{ml})$, indicating that dicycloplatin solution may be kept stable for a longer time. The active antineoplastic component of dicycloplatin is [cisPt $\left.\left(\mathrm{NH}_{3}\right)_{2}\left(\mathrm{H}_{2} \mathrm{O}\right)_{2}\right]^{2+}$.

In preclinical studies, dicycloplatin exerted a potent anticancer effect on hepatocellular carcinoma, gastric cancer, ovarian cancer, melano$\mathrm{ma}$ and NSCLC in vitro and in vivo, with relatively low toxicities $[12,13]$. Based on these results, the China State Food and Drug Administration (SFDA) granted a phase I study of dicycloplatin in 2003 (approval document No. 2003L00508). This clinical trial was subsequently conducted in Cancer Center, Sun Yat-Sen University, China. Twenty-nine patients were enrolled between February 2004 and October 2005, including 10 patients with nasopharyngeal carcinoma, 8 patients with colorectal cancer, 7 patients with NSCLC, 1 patient with synovial sarcoma, 1 patient with malignant schwannoma, 1 patient with breast cancer and 1 patient with Hodgkin lymphoma. In this phase I study, the maximum tolerated dose (MTD) of dicycloplatin was $650 \mathrm{mg} / \mathrm{m}^{2}$, with a half-life about $80 \mathrm{~h}$. The recommended dose of dicycloplatin as a single agent for a phase II study was $550 \mathrm{mg}$ / $\mathrm{m}^{2}$, and the recommended dose in combination chemotherapy was $450 \mathrm{mg} / \mathrm{m}^{2}$. Adverse events were mainly in grade 1 to 2 . Grade 3 or 4 toxicities included nausea/vomiting (29\%), anemia/ thrombocytopenia (7\%) and diarrhea (3\%). This phase I study indicated that dicycloplatin was well tolerated and active against NSCLC. Hence, we designed a randomized, double-blind, open-label, phase II study comparing dicycloplatin plus paclitaxel $(D+P)$ with carboplatin plus paclitaxel $(C+P)$ as first-line treatment for patients with advanced NSCLC.

\section{Material and methods}

\section{Eligibility}

Eligible patients were $\geq 18$ years old, with cytological or histological confirmation of stage IIIB (with pleural effusion) and stage IV NSCLC [14]. 
Patients should have measurable disease and an Eastern Cooperative Oncology Group (ECOG) performance status of 0 to 2 , with a life time $\geq 3$ months. Additional eligible criteria included a leukocyte count $\geq 4,000 / \mu \mathrm{l}$, a neutrophil count $\geq 1,500 / \mu \mathrm{l}$, a platelet count $\geq 100,000 / \mu \mathrm{l}$, a hemoglobin level $\geq 100 \mathrm{~g} / \mathrm{l}$, a bilirubin level $\leq$ the upper limit of normal (ULN), a serum creatinine level $\leq$ the ULN, and transaminase level $\leq 2.5 \times$ the ULN. Contraception measures were taken in female patients of childbearing age during the period of therapy and within 3 months after treatment. Patients who received prior chemotherapy, radiotherapy or biologic therapy for NSCLC, had documented brain and meninx metastases, had a major operation within 4 weeks before this trial or had a significant history of cardiac disease or other active uncontrolled diseases were excluded. However, relapsed tumor after an operation and adjuvant chemotherapy with non-platinum drugs was permitted if completed at least 6 months before registration. Patients who previously had a malignancy within 5 years were also excluded except for basal cell carcinoma, cervical carcinoma in situ or prostate carcinoma in situ. Patients who were during the pregnant or lactation period, allergic to paclitaxel or platinum, abused alcohol and substances, or had primary organ failure were not eligible.

\section{Treatment plan}

This randomized, double-blind, phase II study was approved by local ethics committees and was conducted according to the Declaration of Helsinki. All patients provided informed written consent. Central randomization was done by a clinical research organization (CRO; MDS Parma Services (China) Inc, Beijing, China) via email or telephone in a double-blind fashion such that the investigator and patient did not know the treatment assignment. Patients were stratified according to histological subtype (squamous cell carcinoma; nonsquamous cell carcinoma), disease stage (IIIB; IV) and ECOG performance status $(0-1 ; 2)$. During the study, physicians and other participants were not masked to the identity of the study treatment. Patients were randomly assigned in a $1: 1$ ratio to receive dicycloplatin $450 \mathrm{mg} / \mathrm{m}^{2}$ IV over $1 \mathrm{~h}$ or carboplatin AUC = $5 \mathrm{IV}$ over $1 \mathrm{~h}$, in combination with paclitaxel $175 \mathrm{mg} / \mathrm{m}^{2}$ IV over $3 \mathrm{~h}$ every 3 weeks for up to 4 to 6 cycles. Patients with responding or stable disease after 4 cycles of chemotherapy were allowed to continue treatment for another 2 cycles. Toxicities were recorded and classified in the light of the National Cancer Institute Common Terminology Criteria for Adverse Events (NCl-CTCAE) version 3.0. Strict guidelines were used for dose adjustment or treatment inter- ruption caused by toxic effects throughout study treatment. Grade 3/4 hematologic or non-hematologic toxicities associated with chemotherapy were managed with dose reductions to $75 \%$ for dicycloplatin and paclitaxel and AUC $=4$ for carboplatin for the first time. If the above-mentioned toxicities recurred after the first dose reduction, the drug dose was reduced again to $75 \%$ for dicycloplatin and paclitaxel and AUC $=3$ for carboplatin. Dose reductions were allowed only twice per patient. However, we did not have patients without any chemical therapy, and patients treated with dicycloplatin, or paclitaxel, or carboplatin only according to the ethics.

\section{Evaluations}

Patient history, physical examination and complete blood work were performed at baseline and before each cycle of treatment. Complete blood count (CBC) was repeated weekly to record potential hematologic toxicities. Computed tomography scans were performed at baseline and after every two cycles of therapy. Tumor response was evaluated every 6 weeks according to the Response Evaluation Criteria in Solid Tumors (RECIST) criteria. Conditions for discontinuation from the study included unacceptable toxicity, progression of disease, therapeutic schedule violation, patient withdrawal, pregnancy or change in sponsor's mind that made the study unavailable.

\section{Clinical data}

The aim of this phase II study was to compare the efficacy of dicycloplatin with that of carboplatin in combination with paclitaxel as first-line therapy for patients with advanced NSCLC. The primary endpoint of this study was response rate. All patients with confirmed disease who were randomly assigned to study arms and had received at least one cycle of chemotherapy were evaluable for response. The safety population consisted of all patients who received at least one cycle of protocol treatments. Average response rate and 95\% confidence interval were calculated separately for each arm of the study.

Secondary endpoints included progression-free survival (PFS), overall survival (OS) and adverse events in the intention-to-treat population. The PFS was defined as time between registration and disease progression or death, with censoring for patients alive without progression at last contact. The OS was defined as time between registration and last contact or death. The cutoff date for PFS and OS data was December 9, 2008, when the last patient had finished his treatment for 6 months. By that time, enough data had been collected to analyze the efficacy and toxicities of study arms. 
K.J. Liu, Z.Z. Guan, Y. Liang, X.Q. Yang, J. Peng, H. Huang, Q.X. Shao, M.Z. Wang, Y.Z. Zhu, C.P. Wu, S.B. Wang, J.P. Xiong, Y.X. Bai, S.Y. Yu, Y. Zhang, X.H. Hu, J.F. Feng, S.X. Wu, S.C. Jiao, C.C. Zhou, J. Wang, H.Y. Wu

\section{Statistical analysis}

Both PFS and OS were expressed as median values. All response rates and disease control rates were shown as percentages and compared with the $\chi^{2}$ test. Estimates of PFS and OS were calculated using the Kaplan-Meier method and two-sid-

Table I. Patients' characteristics

\begin{tabular}{|c|c|c|c|c|}
\hline \multirow[t]{2}{*}{ Characteristics } & \multicolumn{2}{|c|}{$\mathrm{D}+\mathrm{P}(N=118)$} & \multicolumn{2}{|c|}{$C+\mathrm{P}(N=118)$} \\
\hline & $n$ & $\%$ & $n$ & $\%$ \\
\hline \multicolumn{5}{|l|}{ Age: } \\
\hline Median & \multicolumn{2}{|c|}{56} & \multicolumn{2}{|c|}{57} \\
\hline Range & \multicolumn{2}{|c|}{$32-71$} & \multicolumn{2}{|c|}{$34-71$} \\
\hline \multicolumn{5}{|l|}{ Years: } \\
\hline $18-39$ & 4 & 3.39 & 3 & 2.54 \\
\hline $40-55$ & 49 & 41.53 & 51 & 43.22 \\
\hline $56-70$ & 65 & 55.08 & 64 & 54.24 \\
\hline \multicolumn{5}{|l|}{ Gender: } \\
\hline Male & 82 & 69.49 & 93 & 78.81 \\
\hline Female & 36 & 30.51 & 25 & 21.19 \\
\hline \multicolumn{5}{|l|}{ ECOG PS: } \\
\hline 0 & 14 & 11.86 & 11 & 9.32 \\
\hline 1 & 95 & 80.51 & 91 & 77.12 \\
\hline 2 & 9 & 7.63 & 16 & 13.56 \\
\hline \multicolumn{5}{|l|}{ Lung stage: } \\
\hline Stage IIIB & 37 & 31.36 & 46 & 38.98 \\
\hline Stage IV & 81 & 68.64 & 72 & 61.02 \\
\hline \multicolumn{5}{|l|}{ Pathological type: } \\
\hline Squamous & 39 & 33.05 & 43 & 36.44 \\
\hline Nonsquamous & 79 & 66.95 & 75 & 63.56 \\
\hline \multicolumn{5}{|c|}{ Previous medical history: } \\
\hline Yes & 114 & 96.61 & 116 & 98.31 \\
\hline No & 4 & 3.39 & 2 & 1.69 \\
\hline \multicolumn{5}{|l|}{ NSCLC symptoms: } \\
\hline Present & 112 & 94.92 & 115 & 97.46 \\
\hline Absent & 6 & 5.08 & 3 & 2.54 \\
\hline \multicolumn{5}{|c|}{ Number of tumors: } \\
\hline 1 & 74 & 62.71 & 78 & 66.10 \\
\hline 2 & 34 & 28.81 & 30 & 25.42 \\
\hline 3 or more & 10 & 8.48 & 10 & 8.48 \\
\hline
\end{tabular}

No significant differences between $D+P$ and $C+P$ characteristics $D+P-$ dicycloplatin plus paclitaxel, $C+P-$ carboplatin plus paclitaxel ed $95 \%$ confidence intervals were obtained. A two-sided log-rank test was used to compare PFS and OS between D + P and C + P arms. Cox proportional hazards model was used to estimate the hazard ratios for D + P vs. C + P arms.

Using historical data, a median PFS of 4 months was assumed for the carboplatin plus paclitaxel arm [7]. The planned duration of accrual was 6 months, and the planned follow-up time was 1 year. A sample size of 200 patients was designed to provide the study with $85 \%$ power to detect an improvement of 4 months in the median PFS of the patients with a type I error of 0.05 . Considering dropout rate, the sample size planned was 240 patients, with 120 patients in each group. Value of $p<0.05$ was considered statistically significant. SPSS 19.0 (Chicago) was used to perform the statistical analyses.

\section{Results}

\section{Baseline characteristics and treatment}

Between January 23, 2007 and February 29, 2008, 240 patients were enrolled in 15 hospitals in China and randomly assigned to the $D+$ $\mathrm{P}$ arm $(n=120)$ or $\mathrm{C}+\mathrm{P}$ arm $(n=120)$. Patient disposition is described according to CONSORT criteria. The safety issue was assessed in 240 patients since all the patients received protocol treatments in the beginning. Four patients were found to be ineligible, including 1 patient already treated with gefitinib $(D+P)$, one patient with IIIA NSCLC $(D+P)$ and 2 patients with brain metastases $(C+P)$. The remaining 236 patients (118 patients in the $D+P$ arm and 118 patients in the $C+P$ arm) were evaluated in the analysis. There were no statistically significant differences between treatment arms in baseline characteristics (Table I). The median cycles of therapy received in each treatment arms were four per patient. No major differences existed between the two arms concerning dose reduction.

\section{Efficacy}

Response assessments based on per protocol (PP) were adequate in 99 patients (83.9\%) in the $D$ $+\mathrm{P}$ arm and 98 patients (83.1\%) in the $\mathrm{C}+\mathrm{P}$ arm. Reasons for inadequate response data included a bilirubin level > the upper limit of normal (ULN) (1 patient in each arm) and a serum creatinine level > the ULN (1 patient in the D + P arm), lack of computed tomography scans for assessments (10 patients in each arm), receiving only one cycle of therapy (1 patient in the $\mathrm{C}+\mathrm{P}$ arm) and taking other antitumor medicines ( 9 patients in the $D+P$ arm and 12 patients in the $\mathrm{C}+\mathrm{P}$ arm).

As illustrated in Table II, there was no significant difference in objective response between the 
Table II. Efficacy results

\begin{tabular}{|c|c|c|c|c|c|}
\hline \multirow[t]{2}{*}{ Variable } & \multicolumn{2}{|c|}{$\mathrm{D}+\mathrm{P}(N=118)$} & \multicolumn{2}{|c|}{$\mathrm{C}+\mathrm{P}(N=118)$} & \multirow[t]{2}{*}{ Value of $p$} \\
\hline & $n$ & $\%$ & $n$ & $\%$ & \\
\hline \multicolumn{6}{|l|}{ Response: } \\
\hline PR [\%] & 43 & 36.44 & 36 & 30.51 & 0.33 \\
\hline SD [\%] & 58 & 49.15 & 59 & 50.00 & 0.43 \\
\hline PD [\%] & 7 & 5.93 & 15 & 12.71 & 0.19 \\
\hline Non-evaluable & 10 & 8.47 & 8 & 6.78 & 0.76 \\
\hline Response rates [\%] & \multicolumn{2}{|c|}{36.44} & \multicolumn{2}{|c|}{30.51} & 0.04 \\
\hline $95 \% \mathrm{Cl}$ & \multicolumn{2}{|c|}{$27.76-45.12$} & \multicolumn{2}{|c|}{$22.20-38.82$} & \\
\hline Disease control rates [\%] & \multicolumn{2}{|c|}{85.59} & \multicolumn{2}{|c|}{80.51} & 0.02 \\
\hline $95 \% \mathrm{Cl}$ & \multicolumn{2}{|c|}{$79.26-91.93$} & \multicolumn{2}{|c|}{$73.36-87.66$} & \\
\hline PFS, median [months] & \multicolumn{2}{|c|}{5.6} & \multicolumn{2}{|c|}{4.7} & 0.31 \\
\hline $95 \% \mathrm{Cl}$ & \multicolumn{2}{|c|}{$4.9-6.3$} & \multicolumn{2}{|c|}{$4.2-5.2$} & \\
\hline 6 months [\%] & \multicolumn{2}{|c|}{43} & \multicolumn{2}{|c|}{33} & 0.19 \\
\hline Survival, median [months] & \multicolumn{2}{|c|}{14.9} & \multicolumn{2}{|c|}{12.9} & 0.37 \\
\hline $95 \% \mathrm{Cl}$ & \multicolumn{2}{|c|}{$12.4-17.7$} & \multicolumn{2}{|c|}{$10.9-15.1$} & \\
\hline 1 year [\%] & \multicolumn{2}{|c|}{58} & \multicolumn{2}{|c|}{56} & 0.90 \\
\hline
\end{tabular}

Response rates were based on intention to treat (ITT). $D+P$-dicycloplatin plus paclitaxel, $C+P$-carboplatin plus paclitaxel, $P R-p a r t i a l$ remission, $S D$ - stable disease, $P D$ - progression disease, $P F S$ - progression-free survival, $C I$-confidence interval

$\mathrm{D}+\mathrm{P}$ arm (95\% Cl: 27.76 to 45.12$)$ and the $\mathrm{C}+\mathrm{P}$ $\operatorname{arm}(95 \% \mathrm{Cl}: 22.20$ to 38.82$)(p=0.33)$. In subgroup analyses, there was a statistical difference in the responses rates (RR) $(36.44 \%$ vs. $30.51 \%$, $p=0.04)$ and disease control rate (DCR) $(85.59 \%$ vs. $80.51 \%, p=0.02$ ) between the two groups.

As for the median PFS and 6-month PFS rates, it was not statistically different between the $D+P$ group and C + P group (5.6 months vs. 4.7 months,

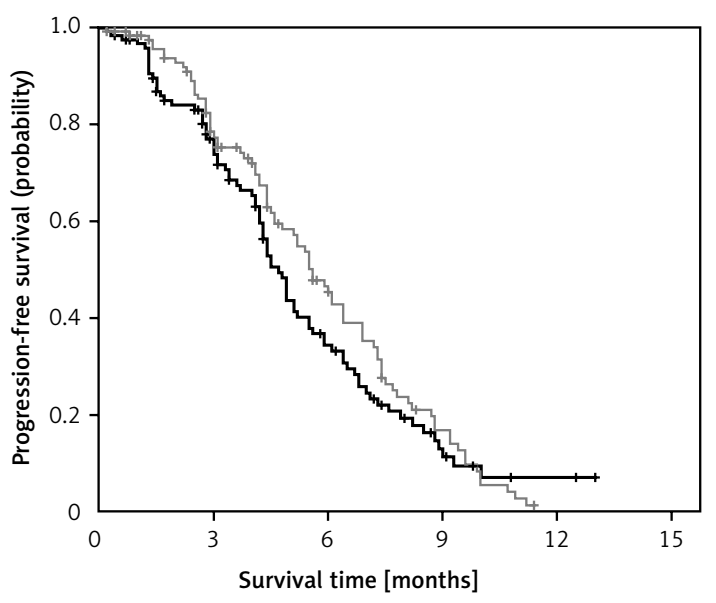

- D + P, median $=5.6$ months $-C+P$, median $=4.7$ months Long-rank $p=0.31$

Figure 1. Kaplan-Meier curves for progression-free survival (PFS) $p=0.31$ and $43 \%$ vs. $33 \%, p=0.19$, respectively) (Figures 1 and 2). Furthermore, there were also no significant differences in the 1-year survival rate ( $58 \%$ vs. $56 \%, p=0.90$ ), PFS and OS between the two groups (Table II).

\section{Adverse events}

Main toxicities possibly related to the therapy are listed in Table III. There were 114 episodes of

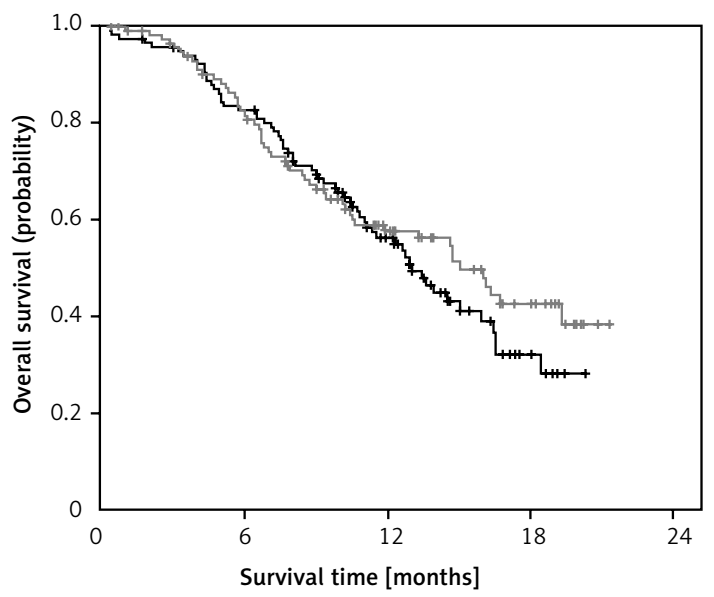

$-\mathrm{D}+\mathrm{P}$, median $=14.9$ months $-\mathrm{C}+\mathrm{P}$, median $=12.9$ months Long-rank $p=0.37$

Figure 2. Kaplan-Meier curves for overall survival (OS) 
K.J. Liu, Z.Z. Guan, Y. Liang, X.Q. Yang, J. Peng, H. Huang, Q.X. Shao, M.Z. Wang, Y.Z. Zhu, C.P. Wu, S.B. Wang, J.P. Xiong, Y.X. Bai, S.Y. Yu, Y. Zhang, X.H. Hu, J.F. Feng, S.X. Wu, S.C. Jiao, C.C. Zhou, J. Wang, H.Y. Wu

Table III. Treatment-related adverse events

\begin{tabular}{|c|c|c|c|c|}
\hline \multirow[t]{3}{*}{ Adverse events } & \multicolumn{2}{|c|}{$\begin{array}{c}D+P \\
(N=118)\end{array}$} & \multicolumn{2}{|c|}{$\begin{array}{c}C+P \\
(N=118)\end{array}$} \\
\hline & $\begin{array}{c}\text { Grade } \\
3\end{array}$ & $\begin{array}{c}\text { Grade } \\
4\end{array}$ & $\begin{array}{c}\text { Grade } \\
3\end{array}$ & $\begin{array}{c}\text { Grade } \\
4\end{array}$ \\
\hline & $n$ & $n$ & $n$ & $n$ \\
\hline Neutropenia & 41 & 34 & 33 & 40 \\
\hline Lymphopenia & 1 & 0 & 4 & 0 \\
\hline Thrombocytopenia & 5 & 0 & 2 & 1 \\
\hline Anemia & 8 & 2 & 4 & 0 \\
\hline Dizziness & 0 & 0 & 1 & 0 \\
\hline Fever & 0 & 0 & 2 & 1 \\
\hline Pulmonary infection & 1 & 0 & 2 & 0 \\
\hline Hyperglycemia & 0 & 0 & 2 & 0 \\
\hline Fatigue & 1 & 0 & 1 & 0 \\
\hline Nausea & 0 & 0 & 1 & 0 \\
\hline Vomiting & 2 & 0 & 1 & 0 \\
\hline Alopecia & 2 & 2 & 2 & 1 \\
\hline Anorexia & 0 & 1 & 1 & 0 \\
\hline Hypoproteinemia & 0 & 0 & 1 & 0 \\
\hline Allergic shock & 1 & 1 & 1 & 0 \\
\hline Constipation & 0 & 0 & 1 & 0 \\
\hline Paclitaxel allergy & 2 & 0 & 2 & 0 \\
\hline Flatulence & 0 & 0 & 1 & 0 \\
\hline Cough aggravation & 0 & 0 & 1 & 0 \\
\hline Extremities numbness & 1 & 0 & 1 & 0 \\
\hline Diarrhea & 1 & 0 & 0 & 1 \\
\hline Rash & 0 & 0 & 1 & 0 \\
\hline Pruritus & 0 & 0 & 0 & 1 \\
\hline $\mathrm{ALT} \uparrow$ & 1 & 0 & 1 & 0 \\
\hline$\gamma-\mathrm{GT} \uparrow$ & 0 & 0 & 1 & 0 \\
\hline Muscles or joints pains & 5 & 0 & 3 & 0 \\
\hline Hypokalemia & 0 & 2 & 0 & 0 \\
\hline
\end{tabular}

Grade 5 events were not included in this table. Two patients experienced grade 5 events: 1 with asphyxia in the $D+P$ arm and 1 with sudden death in the $C+P$ arm, which were mainly attributed to progression of NSCLC. $D+P$ - dicycloplatin plus paclitaxel, $C+P$ - carboplatin plus paclitaxel

grade $3 / 4$ adverse events in the $D+P$ arm, as compared with 115 episodes in the $C+P$ arm $(p=0.99)$. The most common grade $3 / 4$ adverse event was hematologic toxicity, with 91 episodes in the $D+$ $\mathrm{P}$ arm and 84 episodes in the $\mathrm{C}+\mathrm{P}$ arm $(p=0.93)$. Grade $3 / 4$ hematologic toxicities observed in the study were neutropenia (63.56\%), anemia (8.47\%), thrombocytopenia (4.24\%) and lymphopenia $(0.85 \%)$ in the $\mathrm{D}+\mathrm{P}$ arm and neutropenia (61.86\%), anemia (3.39\%), lymphopenia (3.39\%) and thrombocytopenia (2.54\%) in the C + P arm. Grade 5 toxicities included 1 patient with asphyxia $(D+P)$ and 1 patient with sudden death $(C+P)$, which were mainly attributed to progression of
NSCLC. Fourteen patients in the study had severe adverse events, including asphyxia (1 patient), neutropenia (1 patient), pulmonary infection (2 patients), paclitaxel allergy (1 patient) and anaphylactic shock (1 patient) in the $D+P$ arm and neutropenia (1 patient), fever (1 patient), pulmonary infection (2 patients), respiratory failure (1 patient), blindness (1 patient), anaphylactic shock (1 patient) and sudden death (1 patient) in the $\mathrm{C}+\mathrm{P}$ arm $(p=0.82)$.

\section{Discussion}

Platinum-based chemotherapy improved the overall survival of patients with advanced NSCLC, producing a median survival time reaching 1 year [3]. Bevacizumab, a monoclonal antibody against VEGFR, enhanced median overall survival to about 12 months when combined with carboplatin plus paclitaxel for nonsquamous NSCLC patients, with risk of increased toxicities and treatment-related deaths [15]. Gefitinib and erlotinib, two EGFR tyrosine kinase inhibitors, demonstrated potent efficacy against advanced NSCLC as single treatment. However, when combined with chemotherapy, neither drug showed further benefits to patients with advanced NSCLC [16, 17]. Although therapeutic methods developed rapidly, platinum-based twodrug chemotherapy was still extensively used in the clinic.

Dicycloplatin is a novel platinum derivative synthesized in China. In this study, we found that the efficacy of dicycloplatin was similar to that of carboplatin when combined with paclitaxel, with a response rate of about $30 \%$ in each arm, which was similar to the reports of previous studies [18-22] (Table II). Disease control rates were also comparable between $D+P$ and $C+P$ arms. These results indicated that dicycloplatin had the same potency as carboplatin in treating patients with advanced NSCLC. Moreover, in patients with squamous carcinoma, both response rate and disease control rates were significantly higher in the $D+P$ arm, which suggested that dicycloplatin may be more efficacious than carboplatin for the treatment of advanced squamous NSCLC. As known to us, there are less effective drugs for squamous NSCLC compared to lung adenocarcinoma. On one hand, due to the serious hemorrhagic events in the phase II study of bevacizumab [15], patients with squamous NSCLC were inappropriate for first-line therapy of carboplatin and paclitaxel plus bevacizumab; on the other hand, as the EGFR gene rarely mutates in squamous NSCLC [23], tyrosine kinase inhibitors such as gefitinib and erlotinib only had limited efficacy for these patients. Under such circumstances, the emergence of dicycloplatin might be beneficial to patients with advanced squamous cell NSCLC. 
The median PFS for $D+P$ was comparable to that of $C+P$ (Table II and Figure 1), which was consistent with previous reports [24-27]. The median OS was slightly increased in D + P, as compared with that in $\mathrm{C}+\mathrm{P}$ (Table II and Figure 2). The median OS in each arm exceeded 1 year, possibly due to the young population and good performance status of patients in the study. However, there was no statistical difference in the median PFS and median OS between the two groups. One probable reason was that the number of patients enrolled in this study was relatively small. Therefore, a phase III study is needed to further evaluate the efficacy of dicycloplatin combined with paclitaxel in the treatment of advanced NSCLC, especially for patients with squamous cell NSCLC.

The two chemotherapeutic regimes used in this study were generally tolerated (Table III). The frequency and severity of adverse events in the two arms were well balanced. Hematologic toxicities were the most common adverse events. There were more grade 3 toxicities in the $D+P$ arm whereas there were more grade 4 toxicities in the C + P arm (Table III). Still, there was no statistically significant difference between the two arms. Two patients experienced grade 5 events, which were assessed as possibly unrelated to the treatment. There was no treatment-related death reported in the $D+P$ arm. During the study, no grade $3 / 4$ hyperbilirubinemia was detected. The cause and clinical significance of these toxicities need to be assessed and confirmed in further studies. In addition, a recent phase I study of dicycloplatin demonstrated a favorable safety profile at doses between $50 \mathrm{mg} / \mathrm{m}^{2}$ and $550 \mathrm{mg} / \mathrm{m}^{2}$ [28], which permitted clinical trials with more patient samples in future.

In conclusion, this study is the first phase II trial to compare the efficacy and toxicity of $D+P$ with that of $C+P$ in first-line management of patients with stage IIIB and IV NSCLC. We found that patients treated with $\mathrm{D}+\mathrm{P}$ had similar response and survival rates to those treated with $\mathrm{C}+\mathrm{P}$, and toxicities were generally tolerable. A phase III study is required to further confirm the efficacy of this novel combination.

\section{Acknowledgments}

Ke-Jun Liu, Zhong-Zhen Guan and Ying Liang contributed equally to this work.

We thank the doctors, nurses, patients and their family members engaged in this clinical trial for their kind support of our study.

\section{References}

1. Jemal A, Bray F, Center MM, et al. Global cancer statistics. CA Cancer J Clin 2011; 61: 69-90.
2. Kozłowska E, Szewczyk MT, Banaszkiewicz Z, et al. Knowledge of symptoms and diagnostic possibilities of cancer diseases. Arch Med Sci 2011; 7: 304-9.

3. Laskin JJ, Sandler AB. First-line treatment for advanced non-small-cell lung cancer. Oncology (Williston Park) 2005; 19: 1671-6.

4. Schiller JH, Harrington D, Belani CP, et al. Comparison of four chemotherapy regimens for advanced non-smallcell lung cancer. N Engl J Med 2002; 346: 92-8.

5. Scagliotti GV, De Marinis F, Rinaldi M, et al. Phase III randomized trial comparing three platinum-based doublets in advanced non-small-cell lung cancer. J Clin Oncol 2002; 20: 4285-91.

6. Hotta K, Matsuo K, Ueoka H, et al. Addition of platinum compounds to a new agent in patients with advanced non-small-cell lung cancer: a literature based metaanalysis of randomised trials. Ann Oncol 2004; 15: 1782-9.

7. Zatloukal P, Petruzelka L, Zemanova M, et al. Gemcitabine plus cisplatin vs. gemcitabine plus carboplatin in stage IIIb and IV non-small cell lung cancer: a phase III randomized trial. Lung Cancer 2003; 41: 321-31.

8. Belani CP, Lee JS, Socinski MA, et al. Randomized phase III trial comparing cisplatin-etoposide to carboplatin-paclitaxel in advanced or metastatic non-small cell lung cancer. Ann Oncol 2005; 16: 1069-75.

9. Kelly K, Crowley J, Bunn PA Jr, et al. Randomized phase III trial of paclitaxel plus carboplatin versus vinorelbine plus cisplatin in the treatment of patients with advanced non-small-cell lung cancer: a Southwest Oncology Group trial. J Clin Oncol 2001; 19: 3210-8.

10. Qian J, Shen J, Bai H, Han B. The clinical analysis of paclitaxel at two dose levels plus carboplatin as the firstline treatment in advanced non-small cell lung cancer. Zhongguo Fei Ai Za Zhi 2011; 14: 323-8.

11. Socinski MA, Schell MJ, Peterman A, et al. Phase III trial comparing a defined duration of therapy versus continuous therapy followed by second-line therapy in advanced-stage IIIB/IV non-small-cell lung cancer. J Clin Oncol 2002; 20: 1335-43.

12. Dong MY, Ling LT, Xiao YP, Wen JL, Zheng RS. In vitro and in vivo antitumour activity of dicycloplatin, a new active platinum complex. Chin J Mod Appl Pharm 2007; 24: 352-6.

13. Chang HY, Chang S, Yu FL, Ming YL. Comparison of toxicities of bicycloplatin with cisplatin and carboplatin. Chin J New Drugs 2005; 14: 1156-9.

14. Tsim S, O'Dowd CA, Milroy R, Davidson S. Staging of non-small cell lung cancer (NSCLC): a review. Respir Med 2010; 104: 1767-74.

15. Sandler A, Gray R, Perry MC, et al. Paclitaxel-carboplatin alone or with bevacizumab for non-small-cell lung cancer. N Engl J Med 2006; 355: 2542-50.

16. Herbst RS, Giaccone G, Schiller JH, et al. Gefitinib in combination with paclitaxel and carboplatin in advanced non-small-cell lung cancer: a phase III trial INTACT 2. J Clin Oncol 2004; 22: 785-94.

17. Gatzemeier U, Pluzanska A, Szczesna A, et al. Phase III study of erlotinib in combination with cisplatin and gemcitabine in advanced non-small-cell lung cancer: the Tarceva Lung Cancer Investigation Trial. J Clin Oncol 2007; 25: 1545-52.

18. Han B, Xiu Q, Wang $\mathrm{H}$, et al. A multicenter, randomized, double-blind, placebo-controlled study to evaluate the efficacy of paclitaxel-carboplatin alone or with endostar for advanced non-small cell lung cancer. J Thorac Oncol 2011; 6: 1104-9. 
K.J. Liu, Z.Z. Guan, Y. Liang, X.Q. Yang, J. Peng, H. Huang, Q.X. Shao, M.Z. Wang, Y.Z. Zhu, C.P. Wu, S.B. Wang, J.P. Xiong, Y.X. Bai, S.Y. Yu, Y. Zhang, X.H. Hu, J.F. Feng, S.X. Wu, S.C. Jiao, C.C. Zhou, J. Wang, H.Y. Wu

19. Kubota K, Kawahara M, Ogawara M, et al. Vinorelbine plus gemcitabine followed by docetaxel versus carboplatin plus paclitaxel in patients with advanced nonsmall-cell lung cancer: a randomised, open-label, phase III study. Lancet Oncol 2008; 9: 1135-42.

20. Chen YM, Perng RP, Tsai CM, Whang PJ. A Phase II randomized study of paclitaxel plus carboplatin or cisplatin against chemo-naive inoperable non-small cell lung cancer in the elderly. J Thorac Oncol 2006; 1: 141-5.

21. Ohe Y, Ohashi Y, Kubota K, et al. Randomized phase III study of cisplatin plus irinotecan versus carboplatin plus paclitaxel, cisplatin plus gemcitabine, and cisplatin plus vinorelbine for advanced non-small-cell lung cancer: Four-Arm Cooperative Study in Japan. Ann Oncol 2007; 18: 317-23.

22. Socinski MA, Ivanova A, Bakri K, et al. A randomized phase II trial comparing every 3-weeks carboplatin/ paclitaxel with every 3 -weeks carboplatin and weekly paclitaxel in advanced non-small cell lung cancer. Ann Oncol 2006; 17: 104-9.

23. Miyamae Y, Shimizu K, Hirato J, et al. Significance of epidermal growth factor receptor gene mutations in squamous cell lung carcinoma. Oncol Rep 2011; 25: 921-8.

24. Kosmidis P, Mylonakis N, Skarlos D, et al. Paclitaxel (175 mg/m2) plus carboplatin (6 AUC) versus paclitaxel (225 mg/m2) plus carboplatin (6 AUC) in advanced non-small-cell lung cancer (NSCLC): a multicenter randomized trial. Hellenic Cooperative Oncology Group (HeCOG). Ann Oncol 2000; 11: 799-805.

25. Langer C, Li S, Schiller J, et al. Randomized phase II trial of paclitaxel plus carboplatin or gemcitabine plus cisplatin in Eastern Cooperative Oncology Group performance status 2 non-small-cell lung cancer patients: ECOG 1599. J Clin Oncol 2007; 25: 418-23.

26. Schuette W, Blankenburg T, Guschall W, et al. Multicenter randomized trial for stage IIIB/IV non-small-cell lung cancer using every-3-week versus weekly paclitaxel/carboplatin. Clin Lung Cancer 2006; 7: 338-43.

27. Paccagnella A, Oniga F, Bearz A, et al. Adding gemcitabine to paclitaxel/carboplatin combination increases survival in advanced non-small-cell lung cancer: results of a phase II-III study. J Clin Oncol 2006; 24: 681-7.

28. Li S, Huang $\mathrm{H}$, Liao $\mathrm{H}$, et al. Phase I clinical trial of the novel platin complex dicycloplatin: clinical and pharmacokinetic results. Int J Clin Pharmacol Ther 2013; 51: 96-105. 